\title{
Interaction of carvacrol with the Ascaris suum nicotinic acetylcholine receptors and gamma-aminobutyric acid receptors, potential mechanism of antinematodal action
}

\author{
Saša M. Trailović ${ }^{1}$ - Djordje S. Marjanović ${ }^{1}$ - Jelena Nedeljković Trailović ${ }^{2}$. \\ Alan P. Robertson ${ }^{3} \cdot$ Richard J. Martin ${ }^{3}$
}

Received: 2 April 2015 / Accepted: 29 April 2015 / Published online: 7 May 2015

(C) Springer-Verlag Berlin Heidelberg 2015

\begin{abstract}
Essential plant oils (or their active principles) are safe to use and a potentially attractive alternative to current antiparasitic drugs. In the present study, we tested the effects of carvacrol on the isolated tissues of Ascaris suum and investigated potential interactions with other antiparasitic drugs. We used somatic muscle flaps for contraction assays, as well as for electrophysiological investigations. Carvacrol $300 \mu \mathrm{M}$ highly significantly inhibited contractions caused by $1,3,10$, 30 , and $100 \mu \mathrm{M}$ of $\mathrm{ACh}(p=0.0023, p=0.0002, p=0.0002$, $p<0.0001$, and $p<0.0001)$. The control $\mathrm{EC}_{50}$ for acetylcholine was $8.87 \mu \mathrm{M}\left(\log \mathrm{EC}_{50}=0.95 \pm 0.26\right)$, while $R_{\max }$ was $2.53 \pm 0.24 \mathrm{~g}$. The $\mathrm{EC}_{50}$ of acetylcholine in the presence of $300 \mu \mathrm{M}$ of carvacrol was $27.71 \mu \mathrm{M}\left(\log \mathrm{EC}_{50}=1.44 \pm 0.28\right)$ and the $R_{\max }$ decreased to $1.63 \pm 0.32 \mathrm{~g}$. Furthermore, carvacrol highly significant potentiates inhibitory effect of GABA and piperazine on the contractions induced by ACh. However, carvacrol $(100$ and $300 \mu \mathrm{M})$, did not produce any changes in the membrane potential or conductance of the A. suum muscle cell. While, $300 \mu \mathrm{M}$ of carvacrol showed a significant inhibitory effect on ACh-induced depolarization response. The mean control depolarization was $13.58 \pm 0.66 \mathrm{mV}$ and decreased in presence of carvacrol to $4.50 \pm 1.02 \mathrm{mV}$ $(p<0.0001)$. Mean control $\Delta \mathrm{g}$ was $0.168 \pm 0.017 \mu \mathrm{S}$, while in the presence of $300 \mu \mathrm{M}$ of carvacrol, $\Delta \mathrm{g}$ significantly
\end{abstract}

Saša M. Trailović sasa@vet.bg.ac.rs

1 Department of Pharmacology and Toxicology, Faculty of Veterinary Medicine, University of Belgrade, Belgrade, Serbia

2 Department of Nutrition and Botany, Faculty of Veterinary Medicine, University of Belgrade, Belgrade, Serbia

3 Department of Biomedical Sciences, College of Veterinary Medicine, Iowa State University, Ames, IA, USA decreased to $0.060 \pm 0.018 \Delta \mathrm{S}(p=0.0017)$. The inhibitory effect on contractions may be the explanation of the antinematodal potential of carvacrol. Moreover, inhibition of depolarizations caused by $\mathrm{ACh}$ and reduction of conductance changes directly points to an interaction with the $\mathrm{nAChR}$ in A. suum.

Keywords A. suum · Carvacrol · GABA

\section{Introduction}

Infections of humans and animals with parasitic nematodes are a significant health problem worldwide. Nematodes or roundworms are the most diverse of all animals. Over 28, 000 nematode species have been described of which over 16,000 are parasitic (Hugot et al. 2001). There are many parasitic forms of nematodes, which cause enormous economic damage or physical suffering of animals. Humans themselves are host to about 50 different roundworm species, and they are the causative agents in 6 of the 13 core neglected tropical diseases of humans, for example ascariasis, trichuriasis, hookworm disease, lymphatic filariasis, onchocerciasis, and dracunculiasis (Payne and Fitchett 2010). These human diseases, caused by parasitic nematodes, affect more than 3 billion people (Anthony et al. 2007; Brooker 2010). Animal parasitic nematodes are also a very significant burden on animal welfare and agricultural livestock productivity globally and cause severe economic losses (Paterson and Barber 2007). Some of the most commonly used antinematodal drugs in human and veterinary medicine are cholinergic agonists, which include imidazothiazole (levamisole) tetrahydropyrimidines (pyrantel, morantel, and oxantel), quaternary/tertiary amines (bephenium and tribendimidine), pyridines 
(methyridine), and the amino-acetonitrile derivatives (AADs). The second group of antinematodal drugs is the avermectins, agonists of GABA and glutamate-gated chloride channels in nematodes. Finally, the benzimidazoles have an important place in antinematodal therapy as broad-spectrum anthelmintic compounds that inhibit nematode microtubule formation through b-tubulin binding (Martin et al. 2014; Lacey 1990).

Current antiparasitic pharmacotherapy is faced with several important issues. Reports relating to the resistance of different parasitic nematodes to antiparasitic drugs are becoming common, while the problem that increasing doses of drugs carries a pronounced toxicity. Particularly important for veterinary medicine is the fact that most of antiparasitic drugs require a long withdrawal period after administration in food production animals, which is an important problem, both for veterinarians and farmers. We have listed only the most important reasons that led scientists to look towards plant-based alternatives instead of conventional chemical antiparasitic drugs.

Plants produce essential oils as organic products of secondary metabolism. Essential oils (or their active principles) are safe to use and a potentially attractive alternative to current antiparasitic drugs. It is well documented that plant essential oils demonstrate insecticidal and nematocidal activities against a number of arthropod and worm species (Ellis and Baxendale 1997; Enan 2005; Camurça-Vasconcelos et al. 2007; Barros et al. 2009). There is historical evidence that in the beginning of twentieth century, thymol, the principal component of thyme (Thymus vulgaris L.), was used for the treatment of ascarids and hookworms in humans (Kaplan et al. 2014). Today, more and more attention is given to plantbased functional food/feed against endoparasitic infections, which could replace or potentiate the effects of classical anthelmintic therapy (Kaplan et al. 2014). This special food/feed can contain essential plant oils or their active principles, thus allow the using of functional food/feed against parasitic nematode infection.

We are particularly interested in carvacrol, the active constituent of thyme and oregano essential oils. Hierro et al. (2004) have published that carvacrol is able to act in vitro on L3 larvae of Anisakis simplex at a concentration of $12.50 \mu \mathrm{g} / \mathrm{ml}$. Similar results have been published by AbdelRahman et al. (2013), but this time as a nematocidal effect of carvacrol on the model nematode Caenorhabditis elegans.

In the present study, we tested the effects of different concentrations of carvacrol on the isolated tissues of the large pig nematode Ascaris suum. We used somatic muscle flaps for contraction assays, as well as for electrophysiological investigations. The aim of our study was to determine the nature of the effects of carvacrol in the neuromuscular system of parasitic nematodes, as well as to evaluate potential interactions with other antiparasitic drugs.

\section{Materials and methods}

\section{A. suum}

For the contraction assay, adult female $A$. suum were collected weekly from the slaughterhouse at Vrčin, Belgrade, Serbia. For electrophysiological investigations, adult $A$. suum were collected weekly from the JBS packing plant at Marshalltown, IA, USA. Worms were maintained in Locke's solution, composition (mM): $\mathrm{NaCl} 155, \mathrm{KCl} 5, \mathrm{CaCl}_{2} 2$, $\mathrm{NaHCO}_{3} 1.5$ and glucose 5 , at a temperature of $32{ }^{\circ} \mathrm{C}$. The Locke's solution was changed twice daily, and each batch of worms was used within 4 days of collection.

\section{Muscle flap for contraction}

Ascaris muscle flaps for contractions were prepared by dissecting the anterior part of the worm, $2-3 \mathrm{~cm}$ caudal to the head. After dissection, the lateral line was removed from the edge of the flaps. While, each flap (always the same length of $1 \mathrm{~cm}$ ) was monitored isometrically by attaching a force transducer in an experimental bath maintained at $37^{\circ} \mathrm{C}$, containing $20 \mathrm{ml}$ Ascaris Perienteric Fluid Ringer/APF Ringer (mM): $\mathrm{NaCl}, 23$; Na-acetate, $110 ; \mathrm{KCl}, 24 ; \mathrm{CaCl}_{2}, 6 ; \mathrm{MgCl}_{2}, 5$; glucose, 11; HEPES, 5; pH 7.6, and bubbled with room air. After dissection, the preparations were allowed to equilibrate for $15 \mathrm{~min}$ under an initial tension of $0.5 \mathrm{~g}$. Different concentrations of acetylcholine were then added to the preparation $(1,3$, 10,30 , and $100 \mu \mathrm{M}$ ), and the maximum contraction observed before washing and subsequent application of the next concentration of acetylcholine. The responses for each concentration were expressed in grams (g), produced by each individual flap preparation. The effects of carvacrol $(100$ and $300 \mu \mathrm{M})$, $\operatorname{GABA}(1,3$, and $10 \mu \mathrm{M})$, and piperazine $(300 \mu \mathrm{M})$ on control acetylcholine dose-response plots were determined. Contractions were monitored on a PC computer, using a BioSmart interface, and eLAB software (ElUnit, Belgrade). The system allows real time recording, displaying, and analysis of experimental data. Sigmoid dose-response curves for each individual flap preparation at each concentration of antagonist were described by the Hill equation.

\section{Muscle flap for current-clamp recording}

Ascaris muscle flaps for current-clamp recording were prepared by dissecting the anterior part of the worm, $2-3 \mathrm{~cm}$ caudal to the head. The flap was pinned, cuticle-side down, onto a Sylgard ${ }^{\mathrm{TM}}$-lined chamber, where the intestine was removed. The preparation was microperfused continuously with APF. Application of the perfusate was via a fine microtube placed with a micromanipulator (approximately $500 \mu \mathrm{m}$ ) over the muscle cell bag. The rate of perfusion was $3.0 \mathrm{ml} / \mathrm{min}$, and this allowed rapid change of the solution in the isolated tissue 
bath. The temperature in the chamber was maintained at 32$33{ }^{\circ} \mathrm{C}$. A two-microelectrode current-clamp technique was used for measuring the membrane potential and input conductance changes of the Ascaris muscle cell bags. Micropipettes made from borosilicate glass o.d $1.55 \mathrm{~mm}$, i.d. $0.86 \mathrm{~mm}$, (Clarke Electromedical, Reading, UK) with resistances in the range of 20-30 M $\Omega$ when filled with $3 \mathrm{M}$ potassium acetate were used for recording. Two microelectrodes were carefully inserted into a single muscle cell bag with minimum damage. An Axoclamp 2A amplifier, 1320A Digidata Interface, pClamp 9.0 software (all from Axon Instruments, Union City, CA, USA) and PC desktop computer were used to display, record and analyze the membrane potential and injected current. One micropipette was used for recording of membrane potential, while the second was used for injection of current pulses (hyperpolarizing, $40 \mathrm{nA} ; 500 \mathrm{~ms}$ filtered at $0.3 \mathrm{kHz}$ ). Our somatic muscle preparations had resting membrane potentials greater than $-25 \mathrm{mV}$ and the resting input conductances less than $4 \mu \mathrm{S}$. Acetylcholine was added to the bag region of the cell via the microcatheter in the perfusate for $20 \mathrm{~s}$, while carvacrol $(100$ and $300 \mu \mathrm{M})$ was added to the preparation in the perfusate for at least $5 \mathrm{~min}$ before the application of acetylcholine.

\section{Drugs}

Acetylcholine, carvacrol and GABA were obtained from Sigma-Aldrich Co (St Louis, MO, USA), while piperazine was obtained from Fluka (Sweden). Acetylcholine, GABA, and piperazine were dissolved in the APF-Ringer, while carvacrol was dissolved in the ethanol, with a final concentration of ethanol in the APF-Ringer of $0.1 \% v / v$. When tested, $0.1 \%$ of ethanol in APF-Ringer did not alter the resting activity of preparations and did not alter the drug responses.

\section{Analysis}

In the contraction studies, sigmoid concentration doseresponses were described by the equation as follows: \% response $=1 / 1+\left[\mathrm{EC}_{50} / \mathrm{Xa}\right]^{\mathrm{nH}}$, where $\mathrm{EC}_{50}$ is the concentration of agonist (Xa) producing $50 \%$ of the maximum response and $\mathrm{nH}$ is the Hill coefficient (slope). Prism 5.0 (GraphPad Software, San Diego, CA.) was used to estimate the constants $\mathrm{EC}_{50}$ and $\mathrm{nH}$, by non-linear regression for each preparation. We determined mean contraction responses to each concentration of acetylcholine (control dose-response: CR[Ach]); mean responses to each of the concentrations of acetylcholine in the presence of carvacrol, GABA, and piperazine. Paired $t$ tests were used to test differences between control contractions that were followed by test contractions on the same muscle-flap.

In electrophysiological studies, using one-way ANOVA test, we analyzed the differences in depolarization and change in conductivity of the $A$. suum muscle cells, while differences were considered significant at $p<0.05$. Depolarization was induced by acetylcholine $(10 \mu \mathrm{M})$ and observed before and after the addition of carvacrol $(100$ and $300 \mu \mathrm{M})$. Statistical analysis was done using Graphpad Prism software, while all values are expressed as mean \pm S.E.

\section{Results}

\section{Contractions}

Figure 1a shows a representative recording of the Ascaris muscle flap contractions, induced by increasing concentrations of acetylcholine. When carvacrol was added at concentrations of 100 and $300 \mu \mathrm{M}$ for $5 \mathrm{~min}$, there was no change of basal tone, but acetylcholine-induced contractions were reduced. Carvacrol $100 \mu \mathrm{M}$ produced significant inhibition of contractions induced by 1,3 , and $100 \mu \mathrm{M}$ of ACh $(p=0.0248$, $p=0.0076$, and $p=0.0092$ ) (Table 1 ). Figure $1 \mathrm{~b}$ shows the concentration-response plot of acetylcholine (mean \pm S.E. bars), with and without carvacrol in the experimental bath. The control mean effective concentration $\left(\mathrm{EC}_{50}\right)$ for acetylcholine was $8.87 \mu \mathrm{M}\left(\log \mathrm{EC}_{50}=0.95 \pm 0.26\right)$, while maximal effect $\left(R_{\max }\right)$ was $2.53 \pm 0.24 \mathrm{~g}$. Carvacrol $(100 \mu \mathrm{M})$ did not change the $\mathrm{EC}_{50}$ for acetylcholine, $\mathrm{EC}_{50}=7.66 \mu \mathrm{M}(\log$ $\mathrm{EC}_{50}=0.88 \pm 0.24$ ), but carvacrol did reduce the value of $R_{\max }$ to $2.20 \pm 0.21 \mathrm{~g}$.

A higher concentration of carvacrol exhibited a more pronounced inhibitory effect. Carvacrol $(300 \mu \mathrm{M})$ highly significantly inhibited contractions caused by $1,3,10,30$, and $100 \mu \mathrm{M}$ of ACh $(p=0.0023, p=0.0002, p=0.0002$, $p<0.0001$, and $p<0.0001$ ) (Table 1). The $\mathrm{EC}_{50}$ of acetylcholine in the presence of $300 \mu \mathrm{M}$ of carvacrol was $27.71 \mu \mathrm{M}$ ( $\log \mathrm{EC}_{50}=1.44 \pm 0.28$ ), and the $R_{\max }$ decreased to $1.63 \pm$ $0.32 \mathrm{~g}$. Washing the preparations partially reversed the inhibition, with acetylcholine, $\mathrm{EC}_{50}$ after wash $=14.69 \mu \mathrm{M}(\log$ $\left.\mathrm{EC}_{50}=1.16 \pm 0.19\right)$ and $R_{\max }=2.61 \pm 0.27 \mathrm{~g}$.

Based on previous studies on the potential action of monoterpene compounds of essential oils on the GABA-receptor (Tong and Coats 2012; Tong et al. 2013), we examined the interaction of carvacrol with GABA. Figure 2a shows a representative recording of the A. suum muscle contractions, caused by increasing concentrations of acetylcholine and the inhibitory effect of GABA. When GABA was applied at a concentration of $1 \mu \mathrm{M}$, it did not cause changes in the basal tone of the preparation, but reduced the contractions induced by acetylcholine. Furthermore, the combination of $1 \mu \mathrm{M}$ GABA and $100 \mu \mathrm{M}$ carvacrol, more intensely inhibited contractions induced by acetylcholine, while $10 \mu \mathrm{M}$ GABA and $100 \mu \mathrm{M}$ carvacrol completely blocked contractions. It is interesting that the recovery of contractions after the effect of the $\mathrm{GABA}+$ carvacrol combination, was only partial (Fig. 2b, 
(a)

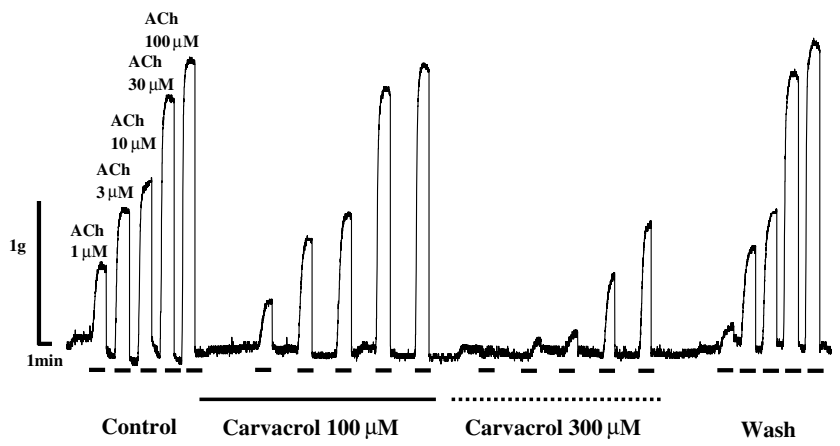

(b)

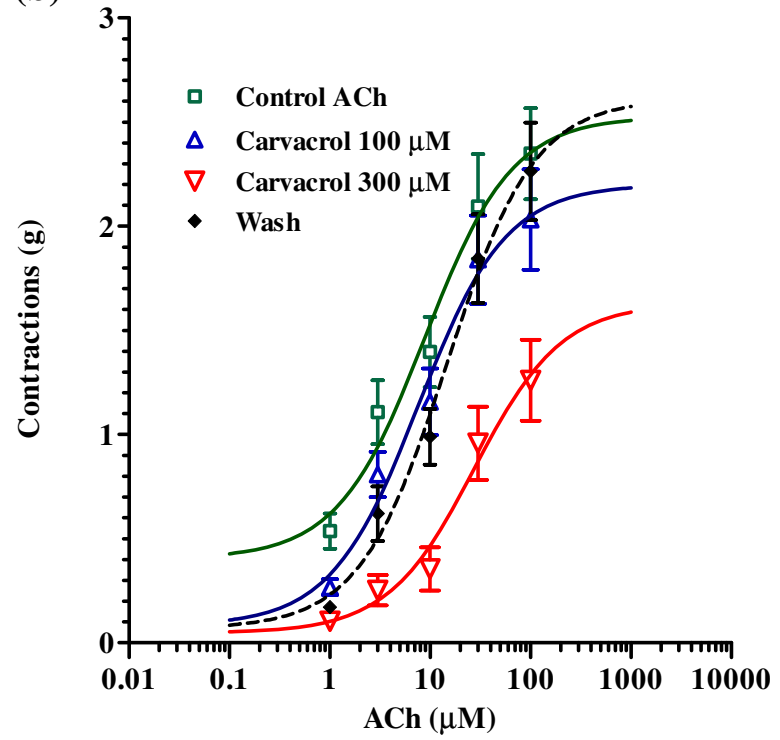

Fig. 1 a Isometric contraction of Ascaris suum muscle strip produced by increasing concentrations of acetylcholine and inhibition of contractions induced by carvacrol. Short bar indicates the application of acetycholine $(1,3,10,30$, and $100 \mu \mathrm{M})$, a full line the presence of carvacrol $100 \mu \mathrm{M}$, and a dashed line the presence of carvacrol $300 \mu \mathrm{M}$. b The concentrationresponse plot for acetylcholine showing mean \pm S.E. bars. Control $(n=8)$; in the presence of $100 \mu \mathrm{M}$ carvacrol $(n=8)$; and in the presence of $300 \mu \mathrm{M}$ carvacrol $(\mathrm{n}=8)$; after washing $(\mathrm{n}=8$, dashed line)

final set of contractions in presented recording). On the other hand, combination of GABA $3 \mu \mathrm{M}$ and carvacrol $300 \mu \mathrm{M}$ produced almost complete blockage of contractions (recording not shown); therefore, there is no possibility of the measuring contractile effects and changes. In accordance with these preliminary results, we decided to test the effect and the interaction, between GABA $3 \mu \mathrm{M}$ and carvacrol $100 \mu \mathrm{M}$ on the contractions induced by increasing concentrations of acetylcholine (Fig. 3a). The application of GABA did not change the basal tone of the A. suum muscle strip, but significantly inhibited the contractions induced by acetylcholine. Control $\mathrm{EC}_{50}$ of acetylcholine in this series of investigation was $7.47 \mu \mathrm{M}\left(\log \mathrm{EC}_{50}=0.87 \pm 0.20\right)$, with $R_{\max }=1.91 \pm 0.37 \mathrm{~g}$. Addition of $3 \mu \mathrm{M}$ GABA had significant inhibitory effect on contractions induced by $1,3,10,30$, and $100 \mu \mathrm{M}$ of $\mathrm{ACh}(p=$ $0.0192, p=0.0032, p=0.0014, p=0.0015$, and $p=0.0098$ ) (Table 2). The value of $\mathrm{EC}_{50}$ of acetylcholine increased to $17.87 \mu \mathrm{M}\left(\log \mathrm{EC}_{50}=1.25 \pm 0.06\right)$, while $R_{\max }$ decreased to $1.34 \pm 0.37 \mathrm{~g}$. Further, intensive inhibition of contractions was observed after administration of a combination of GABA and carvacrol. The inhibitory effect of a combination of GABA+carvacrol on contractions caused by $1,3,10,30$, and $100 \mu \mathrm{M}$ of ACh was highly significant $(p=0.0014, p=$ $0.0009, p=0.0004, p<0.0001, p=0.0014$ ) (Table 2). The $\mathrm{EC}_{50}$ was $25.84 \mu \mathrm{M}\left(\log \mathrm{EC}_{50}=1.42 \pm 0.11\right)$, whereas maximum response $0.95 \pm 0.14 \mathrm{~g}$ (Fig. 3b). Washing of preparations partly reversed contractions towards the control level $\left(\mathrm{EC}_{50}=\right.$ $13.89 \mu \mathrm{M}, R_{\max }=1.84 \pm 0.31$ ). The combination of GABA and carvacrol exhibited a significantly greater inhibitory effect on the contractions induced by acetylcholine, compared with the effect of GABA itself (Table 2). Furthermore, we would like to point out another interesting finding. In some experiments, we did not wash the preparation with APF after adding GABA + carvacrol, but once again incubated with $3 \mu \mathrm{M}$ GABA. Recorded contractions were slightly higher than contractions in the first incubation with GABA, but after washing, contractions were even higher than the control contractions in the beginning of recording (Fig. 2b, last set of contractions).

Piperazine is an anthelminthic especially useful in the treatment of partial intestinal obstruction caused by Ascaris. It has been reported that piperazine mimics the action of GABA, brings about hyperpolarization of Ascaris somatic muscle

Table 1 Mean values of contractions ( \pm S.E., g) of Ascaris suum muscle flaps caused by increasing concentrations of acetylcholine and the inhibitory effect of carvacrol $(100$ and $300 \mu \mathrm{M})$ on these contractions

\begin{tabular}{|c|c|c|c|c|c|}
\hline$n=8$ & $1 \mu \mathrm{M} \mathrm{ACh}$ & $3 \mu \mathrm{M} \mathrm{ACh}$ & $10 \mu \mathrm{M} \mathrm{ACh}$ & $30 \mu \mathrm{M} \mathrm{ACh}$ & $100 \mu \mathrm{M} \mathrm{ACh}$ \\
\hline Control & $0.54 \pm 0.08$ & $1.11 \pm 0.15$ & $1.40 \pm 0.17$ & $2.09 \pm 0.25$ & $2.35 \pm 0.21$ \\
\hline Carvacrol $100 \mu \mathrm{M}$ & $0.26 \pm 0.04 *$ & $0.81 \pm 0.11^{* *}$ & $1.16 \pm 0.16$ & $1.84 \pm 0.21$ & $2.03 \pm 0.24 * *$ \\
\hline Carvacrol $300 \mu \mathrm{M}$ & $0.10 \pm 0.01 * *$ & $0.26 \pm 0.07 * * *$ & $0.35 \pm 0.10^{* * *}$ & $0.96 \pm 0.17 * * *$ & $1.26 \pm 0.19 * * *$ \\
\hline \multirow[t]{2}{*}{ Wash } & $0.17 \pm 0.01$ & $0.62 \pm 0.13$ & $0.99 \pm 0.13$ & $1.84 \pm 0.21$ & $2.26 \pm 0.23$ \\
\hline & $\begin{array}{l}* p=0.0248 \\
* * p=0.0023\end{array}$ & $\begin{array}{l}* * p=0.0076 \\
* * * p=0.0002\end{array}$ & $* * * p=0.0002$ & $* * * p<0.0001$ & $\begin{array}{l}* * p=0.0092 \\
* * * p<0.0001\end{array}$ \\
\hline
\end{tabular}

*Statistically significant difference compared to control 
Fig. 2 a Isometric contraction of Ascaris suum muscle strip produced by application of increasing concentrations of acetylcholine, and inhibition of contractions induced by GABA and carvacol. Short bar indicates the application of acetylcholine $(1,3,10,30$, and $100 \mu \mathrm{M})$, a full line the presence of GABA 1 or $10 \mu \mathrm{M}$, and a dashed line the presence of $300 \mu \mathrm{M}$ carvacrol. b Isometric contraction of Ascaris suum muscle strip, produced by increasing concentrations of acetylcholine, and inhibition of contractions induced by GABA and carvacrol. Short bar indicates the application of acetylcholine $(1,3,10,30$, and $100 \mu \mathrm{M})$, a full line the presence of GABA $(3 \mu \mathrm{M})$, and a dashed line the presence of carvacrol $(100 \mu \mathrm{M})$ (a)
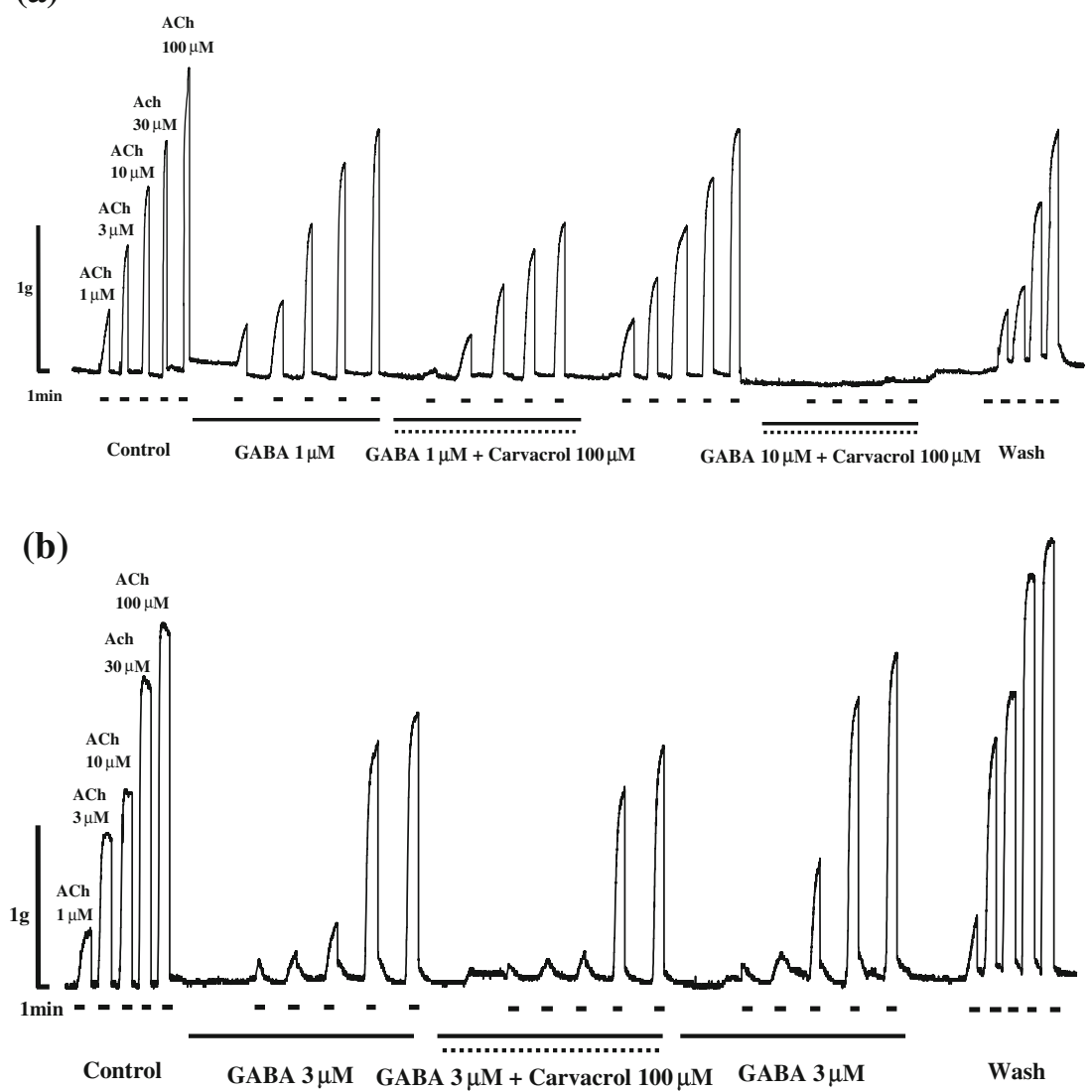

cells, that this is associated with relaxation and flaccid paralysis (Martin 1982). We examined the antagonistic effect of piperazine on contractions induced by acetylcholine, as well as the potential interaction between piperazine and carvacrol. At the beginning, we tested the effect of a combination of piperazine $300 \mu \mathrm{M}+$ carvacrol $300 \mu \mathrm{M}$, but it completely blocked the contractile effects of acetylcholine. Therefore, in order to measure the intensity of inhibition of contraction, we tested a combination of piperazine $300 \mu \mathrm{M}+$ carvacrol $100 \mu \mathrm{M}$. Figure 4a shows a representative recording of the Ascaris muscle flap contractions induced by increasing concentrations of acetylcholine, as well the effects of piperazine $300 \mu \mathrm{M}$ and piperazine $300 \mu \mathrm{M}+$ carvacrol $100 \mu \mathrm{M}$. Piperazine had significant inhibitory effect on contractions induced by 1,3 , and $30 \mu \mathrm{M}$ of ACh $(p=0.0195, p=0.0248$, and $p=0.0015$ ) (Table 3 ). Control $\mathrm{EC}_{50}$ value of acetylcholine in this series of investigations was $11.78 \mu \mathrm{M}\left(\log \mathrm{EC}_{50}=1.07\right.$ $\pm 0.22)$, while the maximal effect $\left(R_{\max }\right)$ was $2.85 \pm 0.65 \mathrm{~g}(n=$ 6). In the presence of $300 \mu \mathrm{M}$ piperazine, comparable values were $\mathrm{EC}_{50}=12.52 \mu \mathrm{M}\left(\log \mathrm{EC}_{50}=1.10 \pm 0.16\right)$ and $R_{\max }=2.08$ $\pm 0.32 \mathrm{~g}$. The inhibitory effect of the combination of these two substances on the contractions induced by acetylcholine (1, 3, $10,30$, and $100 \mu \mathrm{M})$ was even more convincing and highly significant ( $p=0.0072, p=0.0006, p=0.0006, p<0.0001, p=$ $0.0015)$ (Table 3). $\mathrm{EC}_{50}$ was $21.48 \mu \mathrm{M}\left(\log \mathrm{EC}_{50}=1.33 \pm\right.$
0.17 ) and the maximal effect only $0.95 \pm 0.17 \mathrm{~g}$. Similarly as in the experiments with GABA, the combination of piperazine and carvacrol produced a significantly greater inhibitory effect on the contractions caused by acetylcholine, compared with the effect of piperazine itself (Table 3). Recovery after washing was partial, $\mathrm{EC}_{50}$ value of $16.45 \mu \mathrm{M}$ and a maximum contractile effect was $2.35 \pm 0.25 \mathrm{~g}$.

In these investigations, we noticed another interesting finding. After administration of a combination of carvacrol + piperazine, there was enhancement of spontaneous contractile activity of preparations (labeled a, b, c in Fig. 4a). The increase in spontaneous contractility was reversible on washing.

\section{Electrophysiological studies}

In order to analyze the mechanism of antinematodal action of carvacrol in more detail, we tested its effect on the depolarization of A. suum muscle cell induced by acetylcholine. Carvacrol, by itself $(100$ and $300 \mu \mathrm{M})$, did not produce any changes in the membrane potential or conductance of the A. suum muscle cell (Figs. 5a and 6a). However, carvacrol had a rapid (within $5 \mathrm{~min}$ ) reversible inhibitory effect on acetylcholine-induced depolarizations under current-clamp. The lowest concentration of carvacrol tested, $100 \mu \mathrm{M}$, caused no significant (one-way ANOVA), reversible reduction of 


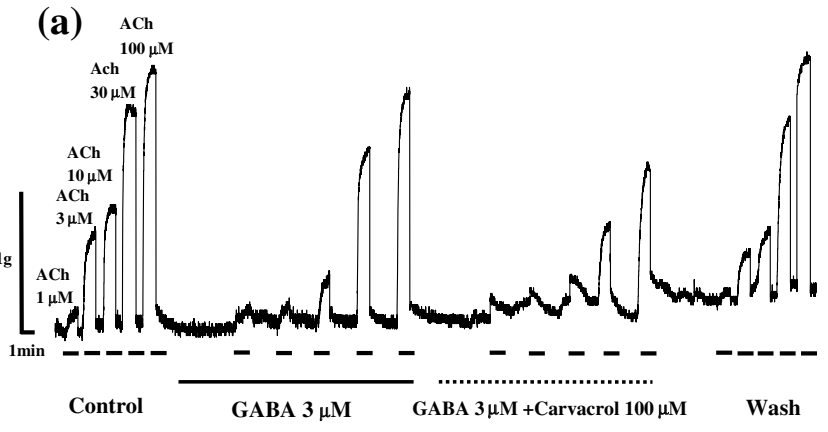

(b)

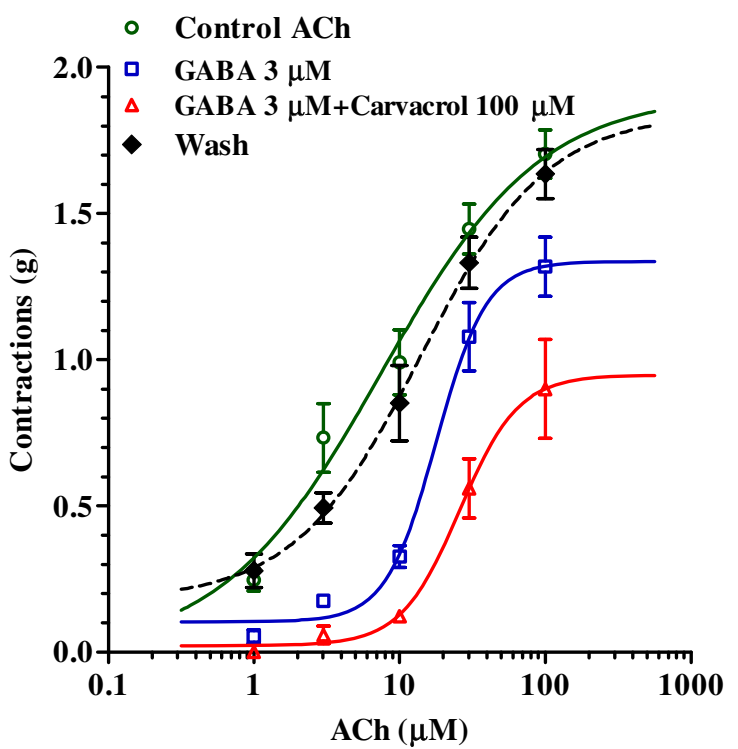

Fig. 3 a Isometric contraction of Ascaris suum muscle strip produced by application of increasing concentrations of acetylcholine, and inhibition of contractions induced by GABA and carvacrol. Short bar indicates the application of acetylcholine $(1,3,10,30$, and $100 \mu \mathrm{M})$, a full line the presence of $3 \mu \mathrm{M} \mathrm{GABA}$, and a dashed line the presence of $100 \mu \mathrm{M}$ carvacrol. b The concentration-response plot of acetylcholine showing mean \pm S.E. bars. Control $(n=6)$; in the presence of $3 \mu \mathrm{M}$ GABA $(n=$ 6 ); in the presence of $3 \mu \mathrm{M}$ GABA and $100 \mu \mathrm{M}$ carvacrol ( $n=6)$; after washing ( $n=6$, dashed line)

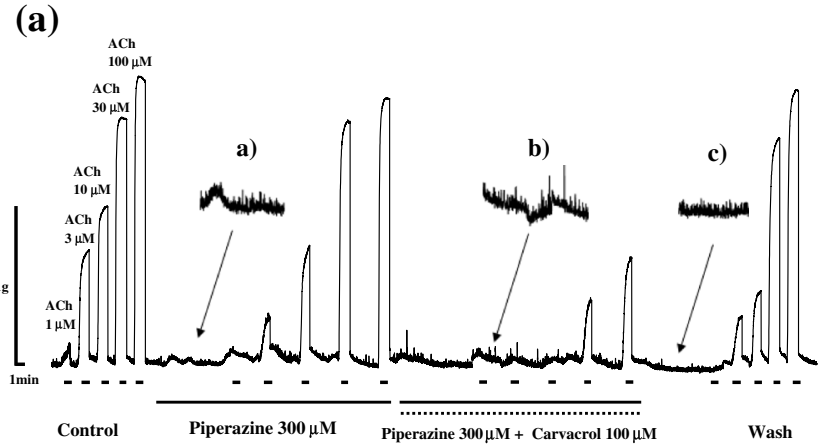

(b)

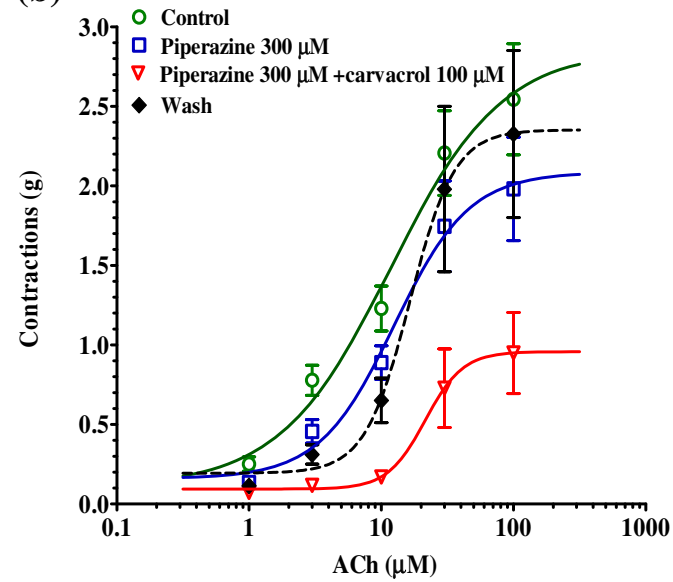

Fig. 4 a Isometric contraction of Ascaris suum muscle strip, produced by increasing concentrations of acetylcholine, and inhibition of contractions induced by piperazine and carvacrol. Short bar indicates the application of acetylcholine $(1,3,10,30$, and $100 \mu \mathrm{M})$, a full line the presence of $300 \mu \mathrm{M}$ piperazine, and a dashed line the presence of $100 \mu \mathrm{M}$ carvacrol. b The concentration-response plot of acetylcholine showing mean \pm S.E. bars. Control $(n=6)$; in the presence of $300 \mu \mathrm{M}$ piperazin $(n=6)$; in the presence of $300 \mu \mathrm{M}$ piperazine and $100 \mu \mathrm{M}$ carvacrol $(n=6)$; after washing $(n=6$, dashed line)

depolarization induced by acetylcholine. Figure 5a shows a representative recording of the inhibition of depolarization produced by a short application of $100 \mu \mathrm{M}$ carvacrol. The mean control value was $10.56 \pm 1.72 \mathrm{mV}$ that decreased in

Table 2 Mean values of contractions ( \pm S.E., g) of Ascaris suum muscle flaps caused by increasing concentrations of acetylcholine and the inhibitory effect of GABA $(3 \mu \mathrm{M})$ and carvacrol $(100 \mu \mathrm{M})$ on these contractions

\begin{tabular}{|c|c|c|c|c|c|}
\hline$n=6$ & $1 \mu \mathrm{M} \mathrm{ACh}$ & $3 \mu \mathrm{M} \mathrm{ACh}$ & $10 \mu \mathrm{M} \mathrm{ACh}$ & $30 \mu \mathrm{M}$ ACh & $100 \mu \mathrm{M}$ ACh \\
\hline Control & $0.24 \pm 0.04$ & $0.73 \pm 0.11$ & $0.99 \pm 0.11$ & $1.45 \pm 0.08$ & $1.70 \pm 0.08$ \\
\hline GABA $3 \mu \mathrm{M}$ & $0.05 \pm 0.02 *$ & $0.18 \pm 0.01 * *$ & $0.32 \pm 0.04 * *$ & $1.08 \pm 0.11^{* *}$ & $1.32 \pm 0.10^{* *}$ \\
\hline GABA $3 \mu \mathrm{M}+$ Carvacrol $100 \mu \mathrm{M}$ & $0 * *$ & $0.06 \pm 0.02 * * *,++$ & $0.12 \pm 0.01 * * *,++$ & $0.56 \pm 0.10^{* * *,+++}$ & $0.90 \pm 0.17^{* *,+}$ \\
\hline \multirow[t]{2}{*}{ Wash } & $0.27 \pm 0.06$ & $0.49 \pm 0.05$ & $0.85 \pm 0.13$ & $1.33 \pm 0.09$ & $2.26 \pm 0.23$ \\
\hline & $\begin{array}{l}* p=0.0192 \\
* * p=0.0014\end{array}$ & $\begin{array}{l}* * p=0.0032 \\
* * * p=0.0009 \\
++p=0.0012\end{array}$ & $\begin{array}{l}* * p=0.0014 \\
* * * p=0.0004 \\
{ }^{++} p=0.0018\end{array}$ & $\begin{array}{l}* * p=0.0015 \\
* * * p<0.0001 \\
{ }^{+++} p=0.0002\end{array}$ & $\begin{array}{l}* * p=0.0098 \\
* * p=0.0014 \\
{ }^{*} p=0.0146\end{array}$ \\
\hline
\end{tabular}

* Statistically significant difference compared to control

${ }^{+}$Statistically significant difference compared to GABA 
Table 3 Mean values of contractions ( \pm S.E., g) of Ascaris suum muscle flaps caused by increasing concentrations of acetylcholine and the inhibitory effect of piperazine $(300 \mu \mathrm{M})$ and carvacrol $(100 \mu \mathrm{M})$ on these contractions.

\begin{tabular}{|c|c|c|c|c|c|}
\hline$n=6$ & $1 \mu \mathrm{M} \mathrm{ACh}$ & $3 \mu \mathrm{M} \mathrm{ACh}$ & $10 \mu \mathrm{M} \mathrm{ACh}$ & $30 \mu \mathrm{M} \mathrm{ACh}$ & $100 \mu \mathrm{M} \mathrm{ACh}$ \\
\hline Control & $0.25 \pm 0.04$ & $0.78 \pm 0.09$ & $1.23 \pm 0.14$ & $2.21 \pm 0.08$ & $2.54 \pm 0.34$ \\
\hline Piperazine $300 \mu \mathrm{M}$ & $0.13 \pm 0.01^{*}$ & $0.46 \pm 0.07^{*}$ & $0.89 \pm 0.10$ & $1.08 \pm 0.11^{* *}$ & $1.98 \pm 0.32$ \\
\hline Piperazine $300 \mu \mathrm{M}+$ Carvacrol $100 \mu \mathrm{M}$ & $0.07 \pm 0.01^{* *,++}$ & $0.12 \pm 0.02 * * *,++$ & $0.17 \pm 0.02 * * *,++$ & $0.56 \pm 0.10^{* * *,+++}$ & $0.95 \pm 0.25^{* *,+}$ \\
\hline \multirow[t]{2}{*}{ Wash } & $0.11 \pm 0.01$ & $0.31 \pm 0.06$ & $0.65 \pm 0.29$ & $1.33 \pm 0.09$ & $2.33 \pm 0.52$ \\
\hline & $\begin{array}{c}* p=0.0195 \\
* * p=0.0072 \\
{ }^{*+} p=0.0012\end{array}$ & $\begin{array}{l}* p=0.0248 \\
* * * p=0.0006 \\
{ }^{*} p=0.0059\end{array}$ & $\begin{array}{c}* * * p=0.0006 \\
++1=0.0008\end{array}$ & $\begin{array}{l}* * p=0.0015 \\
* * * p<0.0001 \\
++p=0.0002\end{array}$ & $\begin{array}{l}* * p=0.0015 \\
+p=0.017\end{array}$ \\
\hline
\end{tabular}

* Statistically significant difference compared to control

${ }^{+}$Statistically significant difference compared to GABA

the presence of carvacrol to $6.75 \pm 1.00 \mathrm{mV}$. Washing returned the depolarization to the control level, $10.35 \pm 2.11 \mathrm{mV}(n=4)$, respectively (Fig. 5b). Although, there was no significant decrease in acetylcholine-induced depolarization, $100 \mu \mathrm{M}$ of carvacrol has significantly reduced the value of conductance change $(\Delta \mathrm{g})$. Control value of $\Delta \mathrm{g}$ was $0.190 \pm 0.021 \mu \mathrm{S}$, while in the presence of carvacrol, $\Delta \mathrm{g}$ decreased to $0.107 \pm$ $0.021 \mu \mathrm{S}(p=0.0207, n=4)$. After washing, $\Delta \mathrm{g}$ returned to $0.175 \pm 0.02 \mu \mathrm{S}$, which was close to the control value (Fig. $5 \mathrm{c}$ ).

Figure 6 a shows a representative recording of acetylcholine-induced depolarizations and inhibition of depolarizations produced by a short application of $300 \mu \mathrm{M}$ carvacrol. The mean control depolarization was $13.58 \pm$ $0.66 \mathrm{mV}$, while this value was decreased in presence of carvacrol to $4.50 \pm 1.02 \mathrm{mV}$. After washing, the average depolarization induced by acetylcholine approached the control value $11.32 \pm 0.84 \mathrm{mV}(n=5)$, respectively. The bar chart in Fig. $6 \mathrm{~b}$ summarizes results from five separate preparations and indicates that carvacrol produced a significant inhibition of depolarization ( $p<0.0001$, one-way ANOVA), which was reversible after washing ( $p<0.0001$, one-way ANOVA). The bar chart in Fig. 6c summarizes results of carvacrol $(300 \mu \mathrm{M})$
Fig. 5 a Representative trace shows depolarizations to three control applications of $10 \mu \mathrm{M}$ acetylcholine (15 s), short bars. The applications of acetylcholine were repeated in the presence $100 \mu \mathrm{M}$ carvacrol (after $5 \mathrm{~min}$ exposure of the preparations to carvacrole) and after washing. b Bar chart summarizing the results shows a nonsignificant reduction in amplitude of acetylcholine depolarizations in the presence of carvacrol $100 \mu \mathrm{M}(n=4, p=$ 0.2483 ). c Bar chart summarizing the results shows a significant reduction in conductance changes $(\Delta \mathrm{g})$ caused by acetylcholine in the presence of carvacrol $100 \mu \mathrm{M}$ $(n=4, p=0.0207)$ (a)

Control

Wash

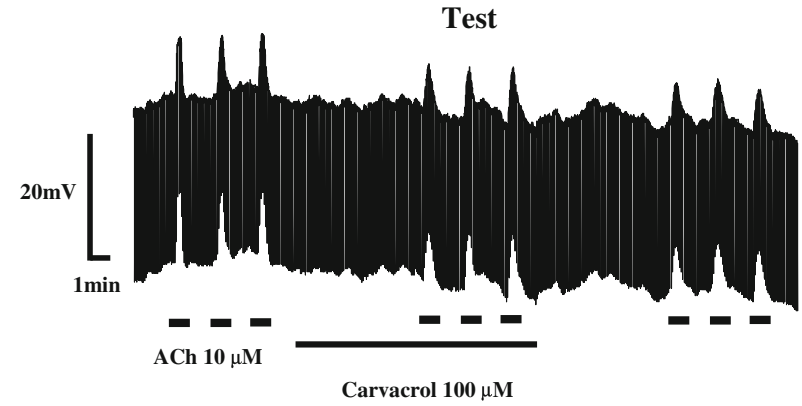

(b)

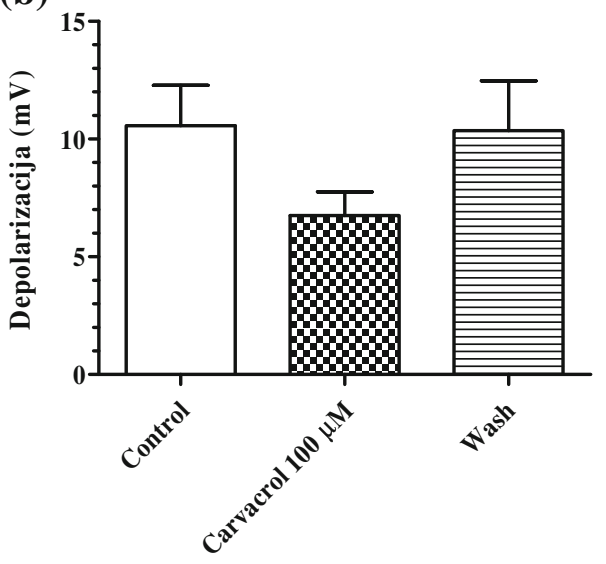

(c)

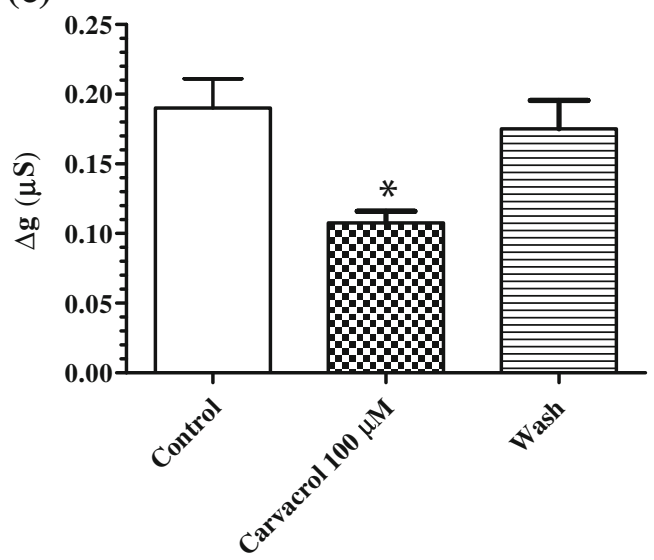


Fig. 6 a Representative trace shows depolarizations to three control applications of $10 \mu \mathrm{M}$ acetylcholine (15 s), short bars. The applications of acetylcholine were repeated in the presence $300 \mu \mathrm{M}$ carvacrol (after $5 \mathrm{~min}$ exposure of the preparations to carvacrole) and after washing. b Bar chart summarizing the results shows a significant reduction in amplitude of acetylcholine depolarizations in the presence of carvacrol $300 \mu \mathrm{M}(n=5$, $p<0.0001)$. c Bar chart summarizing the results shows a significant reduction in conductance changes $(\Delta \mathrm{g})$ caused by acetylcholine in the presence of carvacrol $300 \mu \mathrm{M}$ $(n=5, p=0.0017)$

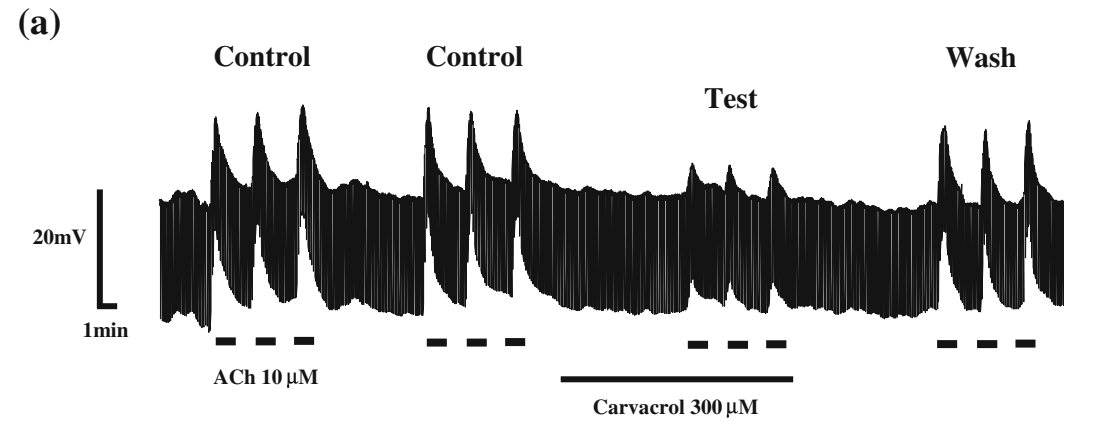

(b)

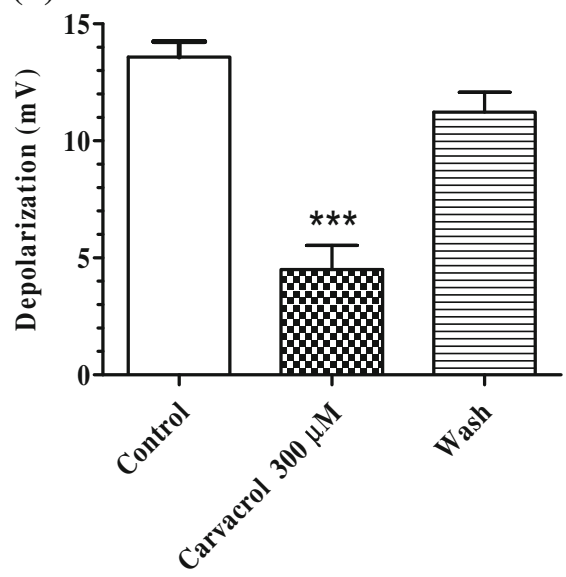

(c)

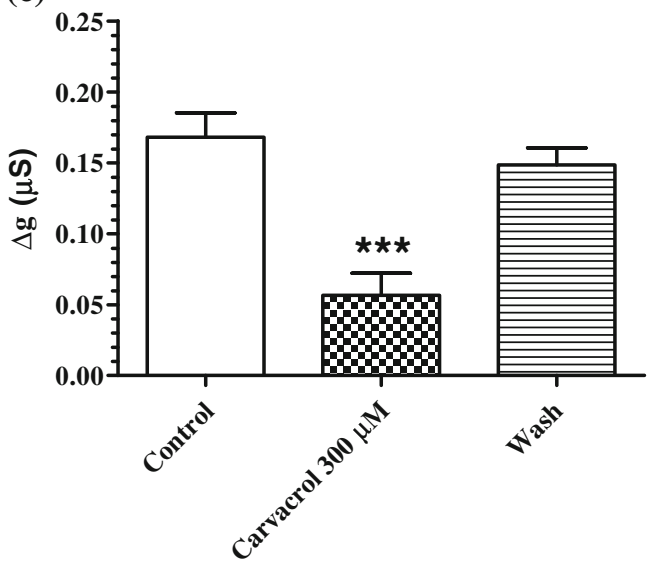

on the conductance changes caused by acetylcholine. Mean control $\Delta \mathrm{g}$ was $0.168 \pm 0.017 \mu \mathrm{S}$, while in the presence of $300 \mu \mathrm{M}$ carvacrol; $\Delta \mathrm{g}$ decreased to $0.060 \pm 0.018 \mu \mathrm{S}$. After washing the conductance changes produced by acetylcholine are almost recovered to the control level, $0.148 \pm 0.012 \mu \mathrm{S}$. The reduction in conductance changes, caused by acetylcholine in the presence of $300 \mu \mathrm{M}$ carvacrol, was significant compared to the control, as well as to the value after washing ( $p=0.0017$, one-way ANOVA).

\section{Discussion}

Carvacrol is present in many plant essential oils, such as thyme oil and oregano oil. It is a phenolic monoterpenoid, which is a class of secondary metabolites found in plant essential oils. In this study, we were interested to investigate the mechanism of antinematodal action of carvacrol. The main reason for this was that several researchers published studies indicating that carvacrol has a high antiparasitic potency. Lei et al. (2010) showed that carvacrol and thymol at concentrations of $330 \mu \mathrm{M}$ caused an $\mathrm{A}$. suum mortality rate of $80 \%$ (in vitro test during $24 \mathrm{~h}$ ). When carvacrol was applied in vitro, at concentrations of 6.25 and $12.50 \mathrm{mg} / \mathrm{ml}$, it caused lethal effects in 90 and $100 \%$ of L3 A. simplex larvae, after 1 and $24 \mathrm{~h}$ of exposition (Hierro et al. 2004). Abdel-Rahman et al. (2013) evaluated the nematocidal activity of 34 terpenoids, commonly found as constituents of plant essential oils, against the free living nematode $C$. elegans. Based on their results, the most efficient nematocidal compound was carvacrol, with $\mathrm{LC}_{50}$ of $3 \mu \mathrm{g} / \mathrm{ml}$.

In our research, carvacrol clearly exhibited an inhibitory effect on the contractions of A. suum induced by acetylcholine. This inhibitory effect on contractions may be the explanation of the antinematodal potential of carvacrol. Carvacrol (100 and $300 \mu \mathrm{M}$ ), by itself did not change the basal tone of muscle flaps, but exhibited the characteristics of a competitive and non-competitive antagonist of acetylcholine-induced contractions. At the lower tested concentration, carvacrol reduced the $R_{\max }$ by $13 \%$, while the higher dose shifted the effective curve to the right, increasing the value for acetylcholine $\mathrm{EC}_{50}$ three times, from 8.87 to $27.70 \mu \mathrm{M}$, and gave a dose-ratio of 3.12. Furthermore, the maximal contractile effect was reduced by more than $30 \%$ (from 2.52 to $1.63 \mathrm{~g}$ ). Previously, there has been a limited amount of published data concerning the mechanism of antinematodal action of carvacrol, showing a possible interaction with a tyramine receptor (Lei et al. 2010). Tyramine inhibits head movements and forward locomotion through the activation of a tyramine-gated chloride channel in C. elegans (Pirri et al. 2009). The inhibitory effect of carvacrol in our studies developed rapidly, after 5 min exposure of the muscle flap, which is much faster than the inhibitory effect 
caused by biogenic amines via their receptors. It is important that tyramine did not alter locomotory waves when injected into A. suum. The lack of any effect of tyramine may reflect the localization of the tyramine-gated channel in the head, but not in the body wall muscle of $A$. suum (Komuniecki et al. 2012). The real functional importance and localization of tyramine-dependent chloride channels in A. suum remains unclear.

Tong and Coats (2012) and Tong et al. (2013) have shown that carvacrol binds to the GABA and tyramine receptors, and thereby can cause an inhibitory effect on the insect nervous system. However, the same authors published data that carvacrol is able to bind nAChRs in the house fly head at a binding site distinct from nicotine and inhibited the binding of $\left[{ }^{14} \mathrm{C}\right]-$ nicotine to the house fly nAChRs non-competitively. The diversity of interactions with different types of receptors in other invertebrates (insects), and the inhibition of contraction in A. suum that we have observed in our experiments, motivated us to investigate the interaction between carvacrol and the major inhibitory neurotransmitter in nematodes - GABA. It has long been known that nematodes have inhibitory GABA-gated chloride channels at the neuromuscular junction (Holden-Dye et al. 1989; Richmond and Jorgensen 1999). These channels are involved in the nematodes sinusoidal movement, with muscles on either side of the body alternately contracting and relaxing. The GABA receptors mediate the relaxation. Martin (1982) demonstrated that, in the bag region of the A. suum muscle cells exist extra-synaptic GABA receptors whose activation gives rise to an increase in Cl- conductance. We found that $1 \mu \mathrm{M}$ GABA is able to inhibit the contractions induced by acetylcholine without altering the basal tone of muscle flap, while the combination of GABA $10 \mu \mathrm{M}$ and carvacrol $100 \mu \mathrm{M}$ completely blocked contractions. In the next series of contraction studies, $3 \mu \mathrm{M}$ GABA shifted the acetylcholine $\mathrm{EC}_{50}$ value to the right, from 7.47 to $17.87 \mu \mathrm{M}$, producing a dose-ratio of 2.39 and reducing the maximum contractile effect by $\approx 30 \%$. GABA is the major inhibitory transmitter in the neuromuscular system of nematodes, and its inhibitory effect on the contractions induced by acetylcholine should be completely non-competitive. However, our results show that one part of the GABA activity is competitive, because concentration-response curves are shifted to the right. One possible explanation for these specific properties of GABA might be connected with its double action. We hypothesize that the first part of action is a consequence of binding to GABA-receptor in the synapses between inhibitory interneurons and motoneurons (synaptic effect). While the second part of action is a postsynaptic effect, involving GABA-receptors on the bag region of muscle cells. The first part can present as competitive inhibition, which immediately activates antagonistic excitatory mechanism (through excitatory interneurons) and second postsynaptic action, causes non-competitive inhibition of contractions.
Increase of the acetylcholine contractile effect after washing of GABA is something that we have already observed, after washing of the neuropeptide AF2 in previous investigations (Trailovic et al. 2005). This phenomenon certainly requires analysis that is more detailed and future research, especially since these have not been observed after washing a combination of GABA + carvacrol.

In the order to verify this hypothesis, we have examined the interaction of piperazine and carvacrol in the inhibition of contractions induced by acetylcholine. Piperazine behaved as a classical non-competitive antagonist in this study. The value of the control acetylcholine $\mathrm{EC}_{50}$ has not changed in the presence of piperazine $300 \mu \mathrm{M}$, but the maximum effect was reduced by $27 \%$. When $100 \mu \mathrm{M}$ of carvacrol was added to the experimental bath with piperazine $(300 \mu \mathrm{M})$, the concentration-response curve for acetylcholine was shifted to the right, and the $\mathrm{EC}_{50}$ value increased from 11.78 to $21.48 \mu \mathrm{M}$, giving a dose-ratio of 1.82 . This combination reduced the $R_{\max }$ by $66.67 \%$, from 2.85 to $0.95 \mathrm{~g}$, respectively. Interestingly, a combination of piperazine + carvacrol increased spontaneous contractile activity of $A$. suum muscle flaps, which was reversible on washing. Carvacrol brings a competitive component to this combination of two antagonists of acetylcholine effects. However, carvacrol reduced the maximum contractile effect, which may point to a very specific mechanism of action and probably multiple binding sites in the neuromuscular system of the nematodes. Possibly, this is the reason that carvacrol $(300 \mu \mathrm{M})$ in combination with piperazine completely blocked the acetylcholine-induced contractions.

In our electrophysiological current clamp studies, we found that carvacrol by itself was not able to cause hyperpolarization, which would be observed if it was directly opening chloride channels in the muscle cells, but the possibility of a presynaptic interaction with interneurons or motoneurons remains. Carvacrol inhibits depolarizations caused by acetylcholine and reduces conductance changes that directly points to an interaction with the nAChR in $A$. suum. This effect was observed at both tested concentrations of carvacrol, 100 and $300 \mu \mathrm{M}$.

The results of the present study are encouraging for the possibility for developing new anthelmintic compounds that may overcome parasite resistance and potentiate the effect of existing drugs. These compounds should have multiple sites of antiparasitic action, which would prevent the development of resistance. Carvacrol is a serious candidate for this type of anthelmintic product and could be included in the content of functional food/feed. Generally regarded as safe, carvacrol can be used for the prevention of nematode infection, or for potentiating the effects of anthelmintic drugs, both in human and veterinary medicine.

Acknowledgments This study was supported by the Ministry of Education and Science Republic of Serbia, Grant No TR31087. 


\section{References}

Abdel-Rahman FH, Alaniz NM, Saleh MA (2013) Nematocidal activity of terpenoids. J Environ Sci Health B 48(1):16-22

Anthony RM, Rutitzky LI, Urban JF, Stadecker MJ, Gause WC (2007) Protective immune mechanisms in helminth infection. Nat Rev Immunol 7:975-987

Barros LA, Yamanaka AR, Silva LE, Vanzeler MLA, Braum DT, Bonaldo J (2009) In vitro larvicidal activity of geraniol and citronellal against Contracaecum sp (Nematoda: Anisakidae). Braz J Med Biol Res 42:918-920

Brooker S (2010) Estimating the global distribution and disease burden of intestinal nematode infections: adding up the numbers? A review. Int J Parasitol 40:1145-1154

Camurça-Vasconcelos ALF, Bevilaqua CML, Morais SM, Maciel MV, Costa CTC, Macedo ITF, Oliveira LMB, Braga RR, Silva RA, Vieira LS (2007) Anthelmintic activity of Croton zehntneri and Lippia sisidoides essential oils. Vet Parasitol 148:288-294

Ellis MD, Baxendale FP (1997) Toxicity of seven monoterpenoids to tracheal mites (Acari: Tarsonemidae) and their honeybee (Hymenoptera: Apidae) hosts when applied as fumigants. J Econ Entomol 90:1087-1091

Enan EE (2005) Molecular response of Drosophila melanogaster tyramine receptor cascade to plant essential oils. Insect Biochem Mol Biol 35:309-321

Hierro I, Valero A, Pérez P, González P, Cabo MM, Montilla MP, Navarro MC (2004) Action of different monoterpenic compounds against Anisakis simplex s.l. L3 larvae. Phytomedicine 11(1):77-82

Holden-Dye L, Krogsgaard-Larsen P, Nielsen L, Walker RJ (1989) GABA receptors on the somatic muscle cells of the parasitic nematode, Ascaris suum: stereoselectivity indicates similarity to a $\mathrm{GABA}_{\mathrm{A}}$-type agonist recognition site. Br J Pharmacol 98(3):841-850

Hugot JP, Baujard P, Morand S (2001) Biodiversity in helminths and nematodes as a field of study: an overview. Nematology 3:199-208

Kaplan RM, Storey BE, Vidyashankar AN, Bissinger BW, Mitchell SM, Howell SB, Mason ME, Lee MD, Pedroso AA, Akashe A, Skrypec DJ (2014) Antiparasitic efficacy of a novel plant based functional food using an Ascaris suum model in pigs. Acta Trop 139:15-22
Komuniecki R, Law WJ, Jex A, Geldhof P, Gray J, Bamber B, Gasser RB (2012) Monoaminergic signaling as a target for anthelmintic drug discovery: receptor conservation among the free-living and parasitic nematodes. Mol Biochem Parasitol 183(1):1-7

Lacey E (1990) Mode of action of benzimidazoles. Parasitol Today 6(4): $112-115$

Lei J, Leser M, Enan E (2010) Nematicidal activity of two monoterpenoids and SER-2 tyramine receptor of Caenorhabditis elegans. Biochem Pharmacol 79(7):1062-1071

Martin RJ (1982) Electrophysiological effects of piperazine and diethylcarbamazine on Ascaris suum somatic muscle. Br J Pharmacol 77(2):255-265

Martin RJ, Puttachary S, Buxton SK, Verma S, Robertson AP (2014) The Conqueror Worm: recent advances with cholinergic anthelmintics and techniques excite research for better therapeutic drugs. J Helminthol 29:1-11

Paterson S, Barber R (2007) Experimental evolution of parasite lifehistory traits in Strongyloides ratti (Nematoda). Proc Biol Sci 274:146-174

Payne L, Fitchett JR (2010) Bringing neglected tropical diseases into the spotlight. Trends Parasitol 26(9):421-423

Pirri JK, McPherson AD, Donnelly JL, Francis MM, Alkema MJ (2009) A tyramine-gated chloride channel coordinates distinct motor programs of a Caenorhabditis elegans escape response. Neuron 62(4): 526-38

Richmond JE, Jorgensen EM (1999) One GABA and two acetylcholine receptors function at the $C$. elegans neuromuscular junction. Nat Neurosci 2(9):791-797

Tong F, Coats JR (2012) Quantitative structure-activity relationships of monoterpenoid binding activities to the housefly GABA receptor. Pest Manag Sci 68(8):1122-1129

Tong F, Gross AD, Dolan MC, Coats JR (2013) The phenolic monoterpenoid carvacrol inhibits the binding of nicotine to the housefly nicotinic acetylcholine receptor. Pest Manag Sci 69(7): 775-780

Trailovic SM, Clark CL, Robertson AP, Martin RJ (2005) Brief application of $\mathrm{AF} 2$ produces long lasting potentiation of $\mathrm{nAChR}$ responses in Ascaris suum. Mol Biochem Parasitol 139(1):51-64 